\title{
The role of seafloor-hydrothermal activity as a driver of marine anoxia
}

\author{
BEN DAVIS BARNES ${ }^{1 *}$ JOHN F. SLACK $^{2 *}$, MARK D. \\ HANNINGTON $^{3}$, NOAH J. PlanaVSKY ${ }^{4}$, LEE R. KUMP ${ }^{1}$ \\ ${ }^{1}$ Dept. Geosciences, Penn State University, University Park, \\ PA 16802, USA (*bdavisbarnes@psu.edu) \\ ${ }^{2}$ U.S. Geological Survey (Emeritus), Reston, VA 20192 USA \\ (*jfslack@usgs.gov) \\ ${ }^{3}$ Dept. Earth and Environmental Sciences, University of \\ Ottawa, Ottawa, ON K1N 6N5 Canada \\ ${ }^{4}$ Dept. Geology \& Geophysics, Yale University, New Haven, \\ CT 06511 USA
}

Numerous Paleozoic biotic crises correlate with sedimentological and geochemical evidence for widespread low- $\mathrm{O}_{2}$ and high- $\mathrm{H}_{2} \mathrm{~S}$, shallow-marine conditions (anoxia and euxinia). Hypothesized factors that promoted the recurrent anoxic events range from external (volcanic outgassing, continental configuration) to internal (biogeochemical cycling) [1]. Recent work has suggested that seafloor-hydrothermal activity, recorded by large volcanogenic massive sulfide (VMS) deposits, may have acted as an additional external driver of basinal-to-regional shifts in shallow-marine redox states [2]. Forming during mid-ocean ridge, arc, and back-arc volcanism, these hydrothermal systems potentially sustained significant fluxes of reductants $\left(\mathrm{Fe}, \mathrm{Mn}, \mathrm{H}_{2} \mathrm{~S}, \mathrm{H}_{2}\right)$ over $\sim 10^{5}$ years, acting as a sink for oxidants and a mechanism for limiting nutrients. Here we provide the first test of ocean redox sensitivity to seafloor-hydrothermal activity using an intermediate-complexity, 3D Earth system model (cGENIE). Across a range of Paleozoic $\mathrm{pO}_{2}$, climate, and nutrient scenarios, our results demonstrate that benthic reductant fluxes associated with VMS mineralization are capable of driving dysoxia and impacting biogeochemical cycling at a basinal to regional scale. These simulations suggest that VMS systems may act as a lever on local redox states, the strength of which is influenced by $\mathrm{O}_{2}$ supply from meridional overturning and strength of the biological pump. Although not likely the sole driver, seafloor-hydrothermal activity potentially played a significant role in strengthening positive feedbacks in biogeochemical and nutrient cycling, setting the stage for Paleozoic marine anoxic-euxinic events.

[1] Meyer and Kump (2008) Annu. Rev. Earth Planet. Sci. 36, 251-288. [2] Grenne and Slack (2019) Miner. Deposita 54, 829-848. 